\title{
Delayed cardiac tamponade by iatrogenic aortic perforation with pacemaker implantation
}

\author{
Charles C. Sticco, DO, a,b and Leonard 0. Barrett, MD, FACS, ${ }^{a, b}$ East Meadow, NY
}

$\mathrm{T}$ he clinical and mechanical complications after permanent pacemaker placement have been cited in the literature. Postpericardiotomy syndrome, ${ }^{1}$ superior vena caval injury, ${ }^{2}$ and ventricular perforation by pacer leads have all been reported. To date, only one instance of aortic perforation caused by pacemaker placement has been described.

This article presents an occurrence of this rare complication occurring 2 weeks after permanent pacemaker implantation.

\section{Clinical Summary}

A 56-year-old white man was brought to the emergency department (ED) for a syncopal episode. The patient reported feeling dizzy and collapsing, with associated headache, nausea, and vomiting. There was no history of chest trauma; the patient's past surgical history was notable for elective placement of a transvenous DDD pacemaker 2 weeks before at a local hospital. Significant past medical history included syncope, bradycardia, hypertension, and coronary artery disease. Current medications included aspirin and metoprolol.

The patient was alert and in mild distress. Pulse was 126 beats/min, blood pressure was $84 / 64 \mathrm{~mm} \mathrm{Hg}$, respiratory rate was 24 breaths $/ \mathrm{min}$, and temperature was $35.6^{\circ} \mathrm{C}$. Physical examination was notable for diaphoresis, cold clammy skin, cyanosis, and tachycardia. Fifteen minutes after arrival, the patient became hypotensive and unresponsive. Blood pressure was $90 \mathrm{mmHg} /$ palpation; dopamine, aggressive fluid replacement, and oxygen stabilized blood pressure to 90/palpation when surgical and cardiology consultants arrived in the ED. Electrocardiography confirmed sinus tachyardia.

Echocardiography revealed a large pericardial effusion with diastolic collapse of the right atrium, collapse of the right ventricle, and respiratory variation on the tricuspid valve in hemolyzation Figures 1 and 2.

The patient was diagnosed with cardiac tamponade and was taken emergently to the operating room on an emergency basis, where a pericardial window was performed through a left anterior thoracotomy approach. After evacuating large amounts of dark red blood and clot surrounding the heart, the blood pressure stabilized. However, bright red blood was observed draining into the pericar-

\footnotetext{
From the Department of Thoracic Surgery, Surgical Critical Care, ${ }^{a}$ and General Surgery, ${ }^{\mathrm{b}}$ Nassau University Medical Center, East Meadow, NY.

Received for publication Aug 7, 2005; accepted for publication Aug 23, 2005.

Address for reprints: Charles C. Sticco, DO, Nassau University Medical Center, 2201 Hempstead Turnpike, East Meadow, NY 11554 (E-mail: csticco@numc.edu).

J Thorac Cardiovasc Surg 2006;131:480-1

$0022-5223 / \$ 32.00$

Copyright $\odot 2006$ by The American Association for Thoracic Surgery doi:10.1016/j.jtcvs.2005.08.060
}

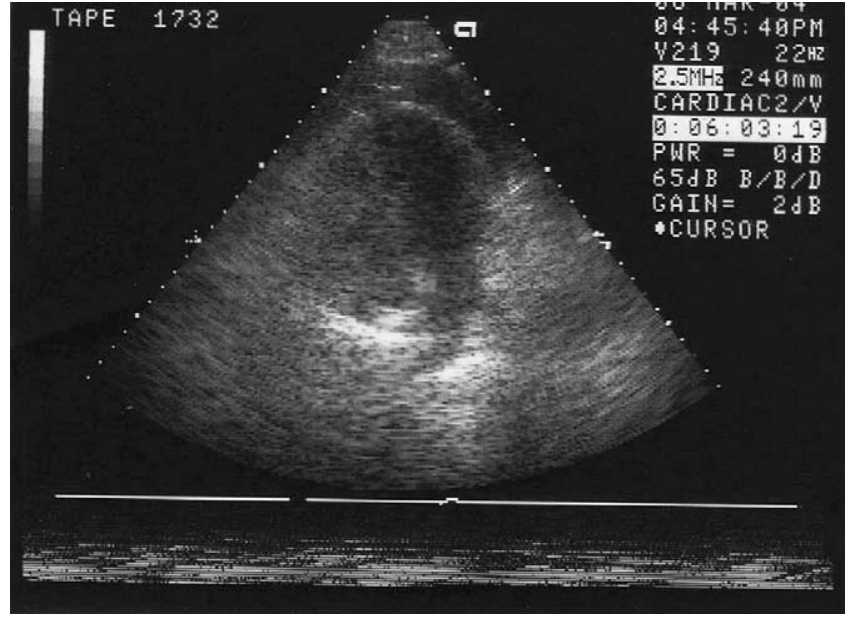

Figure 1. Transthoracic echocardiogram illustrating collapse of Right Ventricle, Left Ventricle and Pericardial Fluid surrounding myocardium.

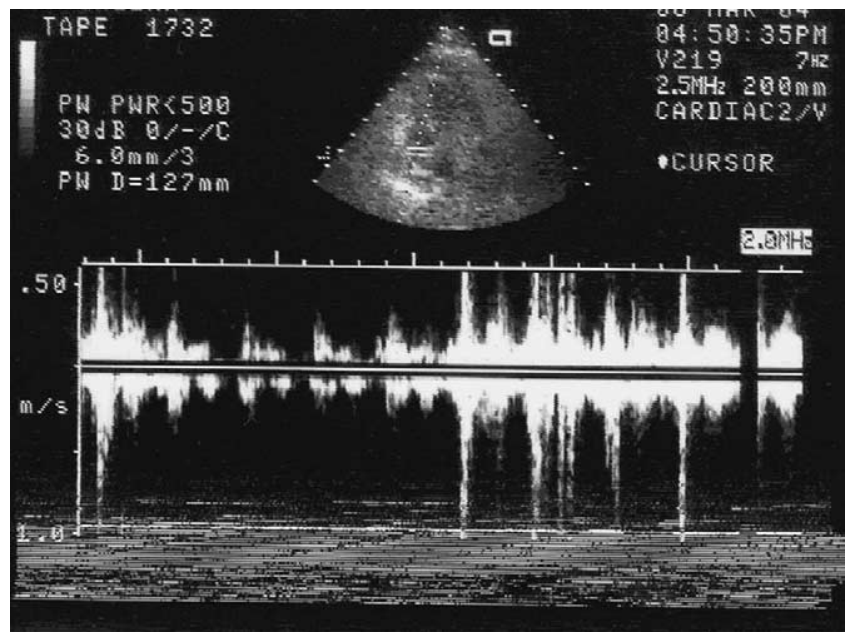

Figure 2. Transthoracic echocardiogram doppler illustrating Tricuspid Valve flow velocity variation with respiration.

dium from a nonvisualized source. An exploratory median sternotomy revealed a small laceration in the right atrium that was not currently bleeding and an ascending aortic laceration with profuse active bleeding. A single cardiovascular Prolene 5-0 suture was placed with a pledget to repair the aortic injury. The patient 
became hypothermic, hypotensive, and hypovolemic due to blood loss. He was transferred to the surgical intensive care unit for management of his hemodynamic instability.

The patient underwent a repeat mediastinal exploration with hematoma evacuation and control of hemorrhage. Over the course of his hospital stay, the patient required 126 units of fresh frozen plasma and 9 units of platelets. He experienced sepsis, hepatic ischemia, atrial fibrillation, and acute renal failure requiring hemodialysis.

During the patient's recovery, a tracheostomy was performed, and his DDD pacemaker was replaced with a VVI pacemaker. After a $3 \frac{1}{2} 2$-month hospital stay, the patient was transferred to a subacute facility for further rehabilitation and management.

Today, the patient has experienced a full recovery.

\section{Discussion}

Previous literature has addressed the effects of delayed cardiac tamponade with right ventricular perforation after pacemaker placement $^{4,5}$ and acute cardiac tamponade with aortic perforation by placement of an atrial pacing lead. ${ }^{3}$ This case illustrates the first documented occurrence of aortic perforation presenting with delayed cardiac tamponade after pacemaker insertion.

The cause of this patient's aortic perforation was undoubtedly the pacing lead puncturing the right atrial wall and injuring the adjacent ascending aorta. Assuming this occurred during the initial placement of the DDD leads, the patient's delayed presentation 2 weeks later suggests that the aortic injury had been occluded by the lead until a positional change caused its displacement and resulting bleed into the pericardium that lead to cardiac tamponade. The less likely possibility in this case, as previously described, ${ }^{3}$ is that a fixating screw protruding from the right atrium caused an acute aortic perforation because of a positional change in the structures of the mediastinum after the patient was discharged to home.

\section{Conclusion}

Two weeks following permanent pacemaker placement, our patient presented to the ED with a syncopal episode. Studies revealed cardiac tamponade caused by right atrial perforation with aortic laceration, which required emergency surgical intervention. This rarely cited complication of pacer lead placement must always be considered in a patient with recent pacemaker insertion.

Prompt, aggressive, and appropriate therapy is essential in managing the associated morbidities that developed in this clinical case. Coordinated multidisciplinary care is needed to ensure the proper management of systemic complications that result in patients with this type of initial presentation. Although this is a rare instance, perhaps earlier postpacemaker implantation follow-up examinations should take place that include imaging for proper lead placement.

\section{References}

1. Spindler M, Burrows G, Kowallik P, Ertl G, Voelker W. Postpericardiotomy Syndrome and cardiac tamponade as a late complication after pacemaker implantation. Pace. 2001;24:1433-4.

2. Samuels LE, Holmes EC, Thomas MP, Berrizbeitia L. Complications following placement or extraction of endovascular pacemaker and defibrillator leads-cardiothoracic surgical intervention: case reports. Heart Surg Forum. 2004;2003-3007,7(3):E236-39.

3. Kashani A, Mehdirad A, Fredman C, Barold SS. Aortic perforation by active-fixation atrial pacing lead. Pace. 2004;27:417-8.

4. Alvarez VB, Alvarez JA, Garcia AM, Martin MF, Morales C. Delayed myocardial perforation following pacemaker implantation. Int $J$ Cardiol. 2004;93:89-91.

5. Gershon T, Kuruppu J, Olshaker J. Delayed cardiac tamponade after pacemaker insertion. J Emerg Med. 2000;18:355-9. 